\title{
Journal of Health Sciences
}

\section{Road to health-care professional's burnout: Poor empathy and impaired workability, are the cause or effect?}

\author{
Alija Sadiković ${ }^{1}$ Azra Kurtić2*, Olivera Sadiković ${ }^{3}$, Maida Mulić ${ }^{4}$ Amela Džubur-Alićs, \\ Munib Smajovićc, Arzija Pašalić6
}

'Department of Radiology and Nuclear Medicine, University Clinical Center Tuzla, Tuzla, Bosnia and Herzegovina, ${ }^{2}$ Department of Psychology of Communication, Faculty of Medicine, University of Tuzla, Tuzla, Bosnia and Herzegovina, ${ }^{3}$ Center for Palliative Care and Pain Treatment, University Clinical Center Tuzla, Tuzla, Bosnia and Herzegovina, ${ }^{4}$ Department of Social Medicine, Faculty of Medicine, University of Tuzla, Tuzla, Bosnia and Herzegovina, ${ }^{5}$ Department of Public Health, Faculty of Medicine, University of Sarajevo, Sarajevo, Bosnia and Herzegovina, ${ }^{6}$ Faculty of Health Studies, University of Sarajevo, Sarajevo, Bosnia and Herzegovina

\begin{abstract}
Introduction: Occupational stress is inevitable, but prolonged and intense can lead to serious health problems. Neglecting this significant aspect of work and inadequate treatment of the first indicators leads to reduced working capacity of health-care professionals.
\end{abstract}

Methods: Assessing the working conditions of 100 health-care professionals regarding stress impact on empathy and workability were the primary goal of this study. A survey was conducted to identify differences between work in intensive care units and other clinical departments all related to empathy, workability, and stress perceiving to determine what is a better predictor of workability.

Results: In the research group, "intensive care units" significantly lower empathy quotients, poorer workability, and different stressors were registered compared to research group named "other departments."

Conclusion: The main conclusion of the study states different dynamics in the working environment of intensive care units compared to other departments that could potentially harm the personal capacity of health-care professionals.

Key words: Intensive care; empathy; workability; stress; burnout

\section{INTRODUCTION}

From a personal life perspective, medicine and the health-care professions are stressful and often

\footnotetext{
*Corresponding author: Azra Kurtić, Department of Psychology of Communication, Faculty of Medicine, University of Tuzla, Tuzla, Bosnia and Herzegovina. E-mail: azra.kurtic@untz.ba
}

Submitted: 21 February 2019/Accepted: 20 August 2019

DOI: https://doi.org/10.17532/jhsci.2019.884

UNIVERSITY OF SARAJEVO FACULTY OF HEALTH STUDIES require a lifestyle that limits participation in social events. A study by Sullivan indicates that health professionals' satisfaction with their patient relationships can serve as a protective factor against occupational stress, burnout, drug abuse, and even suicide attempts which are reported to be unusually high among health-care professionals (1). Most often, stressful situations are caused by the individuals' high volume and complicated nature of work tasks, and different and vague expectations for the 
task. The stated ambivalence of the situation leads to the lack of proper feedback and conflicts of opinion, which creates a pressure of timelines and the need for reorganization of work roles. In this way, both the individual and the organization are damaged.

At the individual level, the consequences are psychological, affective, and behavioral. In the effective area, mood swings are the most common acute stress response, as opposed to decreased satisfaction, mental health disorders, and burnout syndromes that develop as a long-term response to prolonged stress (2). Stressors also manifest negatively at the behavioral level. In stressful situations, attention is diverted, which diminishes working memory capacity. The decline in job performance is not necessarily present because the individual in stress puts more effort into performing tasks, but an increase in violent behavior, interpersonal conflicts, and hostile behavior are possible (3). Mindfulness is determined by the physical and social characteristics of the environment, personality characteristics, and the properties of the cognitive construction of reality. For this reason, the discrepancy between perception and one's desires determines two outcomes in stress: Individual satisfaction and the capacity to cope with stress. Baron-Cohen points out that empathy in patient care stems from a natural desire to care for others (4). Gianakos describes empathy for the patient as a role play, that is, the ability to imagine the health-care provider in the patient's situation (5). Larson and Yaoa summarize the importance of empathy into a "symbol of the health-care profession" (6).

Lewis points out that health-care professionals often perceive empathic relationships with patients as meaningful interpersonal relationships, and in his view, these relationships can serve as resistance against dissatisfaction with the health-care system and occupational burnout (7). At the same time, empathic relationships are a source of intrinsic motivation, which in the form of satisfaction is positioned as a mechanism to cope with the stressful demands of the profession. However, it should be noted that the relationship between health-care provider satisfaction and the number of patient encounters is not linear, that is, there is a saturation point where excessive patient burden leads to stress (8).
The disproportionality of the demands of the environment and the ability of the individual to adequately respond to such demands is the basic operationalization of stress in the concept of discrepancy (9).

Any situation that requires a health-care professional to do what he or she cannot, should not, or does not want is labeled a stressful situation and represents a discrepancy between environmental demands and individual opportunities. Health professionals have a great responsibility for the life and health of people, which, in addition to working conditions, places them in a high-risk population when it comes to stress. Situations such as shift work, 24-hour on-call duty, the responsibility of quick decision-making, and dealing with emotionally exhausting situations are risk factors for health professionals. Cardiovascular diseases, such as high blood pressure, arrhythmia, and ischemic heart disease that are associated with stress, are widespread in healthcare professionals. The diseases of the other systems are not negligible, and the diseases of the musculoskeletal, respiratory, and gastrointestinal systems are particularly emphasized. All of these diseases, in addition to the pronounced symptoms, result in rapid fatigue and emotional irritability (10).

Occupational stress is an important factor in the modern work process as it is associated with increased rates of absenteeism, sick leave, and early retirement. The health-care profession is considered to be a highly stressful profession due to exposure to specific stressors related to the responsibility for the life and health of patients. Levels of stress at physicians' work are known to increase further in pediatric and neonatal intensive care units. In their study, Buddeberg-Fischer et al. point out that employees in these work units experience intense job overload, burnout syndrome, decreased work satisfaction, and thus are more susceptible to psychological distress (11). Occupational stress studies in intensive care units include more specific aspects related to the demands of the work environment, such as emotional exhaustion, burnout, moral distress, and situations related to sudden traumatic events such as the death of a patient. For intensive care unit employees, constant exposure to the distress experienced by the patient and his or her family leads to emotional exhaustion (fatigue). 
Studies that have examined whether workplace stressors are similar or the same for all health professionals point out that factors relevant to health care, along with the organizational arrangements within which health-care professionals work, are equally important determinants of perceived stress. Intensive care units are one of these jobs. Health-care professionals (12) working in intensive care units and emergency admissions are subject to many of the same stressors as health professionals from other departments, but the nature of work at intensive care units and emergency admissions units is different from the others. The phenomenon of empathy and compassion satisfaction as an integral part of it, which entails professional fulfillment for helping others, also plays a significant role in coping with stress. Numerous studies have shown an association between stress and certain illnesses such as emotional exhaustion, physical exhaustion, and low back pain (13). The high demands they face daily, the inability to make independent decisions with health-care professionals, cause a sense of lack of control and increase the risk of coronary artery disease. The high level of stress that health-care professionals face can lead to reduced levels of productivity, reduced quality of work $(14,15)$ and consequently to permanent impairment of work capacity. The work capacity of an individual can be seen in the broader context of employability. It refers to individual and work factors that are relevant to a person's ability to cope with working conditions (16). It is a subjective perception of one's workability. Self-assessment is based on a commitment to work, educational and vocational training, work history, transferable skills, current work status and relationships with work colleagues, social activities, support system and appropriate needs (16) and aims to prevent disability, occupational disease, and work-related illnesses and occupational injuries (17).

This study aims to identify differences in perceptions of work stressors among healthcare workers employed in intensive care units compared to employed healthcare workers in other clinical departments, and their effect on empathy capacity and work capacity.

\section{METHODS}

The present study by design was cross-sectional with a target population of health-care professionals from different clinical departments of the University Clinical Center Tuzla and the Tuzla Health Center. The survey was self-assessed with standardized questionnaires conducted by online. Participants were informed of the study purpose and their participation was voluntary and anonymous.

The study sample included 100 health professionals (50 from intensive care unit and 50 from other clinical departments), including doctors, nurses, and technicians with higher and university levels of education, employed by local University Clinical Center and Health Center.

Participants in the study were grouped into two research groups. The criteria for creating research groups were set by the workplace (intensive care unit and other departments). Intensive care units group included health-care professionals working in such departments intensive care units of clinic for internal medicine, clinic for surgery, anesthesia and resuscitation clinic, gynecology and obstetrics clinic, infectious disease clinic, psychiatry clinic, lung disease clinic, center of palliative care, and pediatric clinic. Participants with the workplace at orthopedics and traumatology clinics, radiology and nuclear medicine clinics, health center, clinics for cardiovascular surgery, clinics for ear, throat, and nose diseases were assigned to research group labeled as "other departments." Within the two groups, participants were observed by gender, working experience, perception of work stressors, the quotient of empathy (Empathy quotient $[\mathrm{EQ}]$ ), and workability index (WAI). The online survey contained general data on participants (clinical ward, gender, and working experience) and standardized questionnaires (Cohen-Baron's empathy questionnaire, questionnaire of workplace stress assessment by health-care professionals, and WAI questionnaire).

Empathy questionnaire by Baron-Cohen and Wheelwright is a 4-point self-assessment scale (18). It consists of 60 items divided into two groups: 40 items (measure empathy) and 20 items are "filter items" that reduce respondents' bias in giving socially desirable answers and focusing on empathy. Half of the scores that measure empathy was formed by denying responses and the other half by affirming, also to eliminate bias in the affirmative/negative responses. The range of empathy scores is set 0-80. 
Correspondent empathy coefficients (EQ) based on points was set (low EQ: 0-32; average EQ 33-52; above-average EQ 53-63; high EQ 64-80).

Questionnaire of workplace stress assessment by health-care professionals in the first part contains general information (gender, age, level of education, occupation, workplace, length of total work experience, length of work experience in the present workplace, and working time). The second part was related to workplace stressors. Participants were offered 37 work stressors about work organization, shift work, career advancement, education, professional requirements, interpersonal communication, and fear of health hazards and harms. Respondents rated the experience of stressors on a Likert-type scale (1- not stressful at all; 2- rarely stressful; 3- sometimes stressful; 4- stressful; and 5- extremely stressful). Stressors are grouped into six factors: (F1 - workplace organization and financial matters; F2 - public criticism and lawsuits; F3 - dangers and harms at work; F4 - conflicts and communication at work; F5 - working hours and shifts, and F6 - professional and intellectual demands.

WAI questionnaire was used to evaluate the subjective rating of workability compared to the best level in life; subjective assessment of workability concerning the physical and mental demands of the workplace; several diagnosed illnesses, the subjective impact of illness on work, sickness over the past year, the personal prognosis of working ability for the next 2 years; and questions about mental health and satisfaction. The total WAI score was categorized as poor workability (7-27), moderate workability (28-36), good working ability (37-43), and excellent working ability (44-49).

Standard Statistical Package (SPSS) version 20.0 was used to analyze the results. Differences between the two studied groups were assessed using a t-test for independent samples and three or more subgroups of participants, one-way analysis of variance. The correlation between the continuous variables was expressed by the value of the Pearson correlation. Statistical significance was set at below 0.05 .

\section{RESULTS}

The total sample in this study consisted of 100 health-care professionals, classified by the workplace into two groups with no statistically significant difference (intensive care units $-47 \%$ and other clinical departments $-53 \% ; \chi_{(1)}^{2}=0.36 ; p=0.54$ ). According to gender structure, men made up $49 \%$ and women $51 \%$ of the sample. Based on work experience, the average length of service recorded was 13 years. No significant difference was observed in the sample of respondents in terms of gender difference, job affiliation to the hospital ward, as well as respondents' length of service $(\mathrm{t}=0.766 ; \mathrm{df}=98$; $p=0.446)$ (Table 1).

The mean values of the empathy score in intensive care units were 39, while in other wards, the average empathy score was about 43 . Although both scores correspond to the average EQ range, in the intensive care unit group, the EQ was significantly lower compared to other research groups. The difference in the perception of work stressors was also evident. Respondents from the intensive care unit group experienced significantly more intense $(p<0.05)$ workplace stressors compared to colleagues working in other departments. The index of workability in both observed workplace departments, on average, corresponds to moderate

TABLE 1. Descriptive characteristics of respondents

\begin{tabular}{lcc}
\hline Characteristics & $\mathrm{n}(\%)$ & $\mathrm{M}(\mathrm{SD})$ \\
\hline Gender & 49 & 1.41 (0.75) \\
$\quad$ Male & 51 & \\
$\quad$ Female & 15 & $13.05(1.52)$ \\
Total working internship (years) & 10 & \\
$<5$ & 13 & \\
$5-10$ & 12 & \\
$11-15$ & 50 & \\
$16-20$ & & \\
$>20$ & 18 & 41.08 (10.04) \\
Empathy coefficients (EQ) & 73 & \\
Low EQ & 7 & \\
Average EQ & 2 & \\
Above-average EQ & & \\
High EQ & 18 & 35.21 (8.1) \\
Workability index & 34 & \\
Poor working ability & 34 & \\
Moderate workability & 14 & \\
Good working ability & 100 & \\
Excellent workability & \\
Total respondents & \\
\hline t (98)=0.766; $\mathrm{P}=0.446 ; \mathrm{EQ}:$ Empathy quotient &
\end{tabular}


workability and does not differ significantly in the two research groups (Table 2).

The workability and empathy of health-care professionals in the intensive care unit are significantly $(p<0.05)$ affected by work stressors from the "Organization of Work and Finance" (F1) group. Stressors from the "Conflicts and communication at work" group (F4) significantly $(p<0.05)$ affected health-care professionals from other departments, while the impact of stressors on empathy did not reach the level of significance (Table 3).

Hierarchical multiple regression was used to evaluate the feasibility of two measures, empathy and work stress, on the ability of health-care professionals employed in intensive care units concerning other clinical units after eliminating the influence of gender and length of service. Preliminary analyzes confirmed that the assumptions of normality, linearity, multicollinearity, and homogeneity were not violated. Model 1 found that the predictors of gender and total working internship explain about $29 \%$ of the variance in workability. The overall model (Model 2) explained $88 \%$ of variance (F [4.96] $=41.48 p<0.001$ ), while empathy and work stress perception explained an additional 59\% of variance $\mathrm{F}(4.96)=6.39 ; p<0.001)$. Only two predictors have statistical significance for predicting workability, where work stress perception had a greater unique contribution $(\beta=0.54 p<0.001)$ than empathic behavior $(\beta=0.39 p<0.001)$ (Table 4).

TABLE 2. Descriptive values of job characteristics by the department of workplace

\begin{tabular}{lcc}
\hline Characteristics & Intensive care unit & Other departments \\
\cline { 2 - 2 } & $\mathrm{M}(\mathrm{SD})$ & $\mathrm{M}(\mathrm{SD})$ \\
\hline Total working internship/years & $12.85(1.63)$ & $13.25(1.42)$ \\
Empathy/score & $39.0(10.81)^{*}$ & $42.92(9.01)$ \\
Work ability/WAI & $34.54(8.36)$ & $35.81(7.95)$ \\
Perception of stress/intensity & $68.56(16.27)^{*}$ & $61.41(19.22)$ \\
Total respondents & 47 & 53 \\
\hline
\end{tabular}

WAl: Workability index; *ANOVA F $=3.67 ; p<0.05$

TABLE 3. Correlation matrix of stress factors, empathy, and workability by workplace

\begin{tabular}{|c|c|c|c|c|c|c|c|c|}
\hline Workplace & F1 & $\mathrm{F} 2$ & F3 & F4 & F5 & F6 & $E Q$ & WAI \\
\hline \multicolumn{9}{|c|}{ Intensive care units } \\
\hline F1 & 1 & $0.62^{* *}$ & 0.11 & $0.43^{* *}$ & $0.35^{*}$ & $0.52^{* *}$ & $0.78^{*}$ & $0.52^{\star}$ \\
\hline F2 & $0.62^{* \star}$ & 1 & 0.22 & $0.61^{* *}$ & $0.58^{* *}$ & $0.64^{* *}$ & 0.10 & -0.65 \\
\hline F3 & 0.11 & 0.22 & 1 & $0.32^{*}$ & 0.27 & 0.29 & 0.29 & -0.04 \\
\hline $\mathrm{F} 4$ & $0.43^{* *}$ & $0.61^{* *}$ & $0.32^{*}$ & 1 & $0.64^{* *}$ & $0.79^{* *}$ & 0.43 & 0.17 \\
\hline F5 & $0.35^{\star}$ & $0.58^{* *}$ & 0.27 & $0.64^{* *}$ & 1 & $0.66^{\star *}$ & -0.28 & 0.59 \\
\hline F6 & $0.52^{* *}$ & $0.64^{* *}$ & 0.29 & $0.79^{\star *}$ & $0.66^{* *}$ & 1 & 0.048 & 0.37 \\
\hline$E Q$ & $0.78^{*}$ & 0.10 & 0.29 & 0.43 & -0.28 & 0.48 & 1 & $0.21^{*}$ \\
\hline WAI & $0.52^{*}$ & -0.65 & -0.04 & 0.17 & 0.59 & 0.37 & $0.21^{*}$ & 1 \\
\hline \multicolumn{9}{|c|}{ Other departments } \\
\hline F1 & 1 & $0.43^{* *}$ & -0.07 & $0.38^{* *}$ & -0.15 & $0.29^{*}$ & 0.17 & 0.87 \\
\hline $\mathrm{F} 2$ & $0.43^{* *}$ & 1 & 0.78 & $0.72^{* *}$ & -0.72 & $0.38^{*}$ & 0.11 & 0.29 \\
\hline F3 & -0.07 & 0.78 & 1 & -0.76 & -0.11 & 0.22 & 0.82 & -0.27 \\
\hline $\mathrm{F} 4$ & $0.38^{* *}$ & $0.72^{\star *}$ & -0.76 & 1 & -0.16 & 0.13 & 0.12 & $0.27^{*}$ \\
\hline F5 & -0.15 & -0.72 & -0.11 & -0.16 & 1 & $0.45^{\star *}$ & -0.25 & 0.14 \\
\hline F6 & $0.29^{*}$ & $0.38^{*}$ & 0.22 & 0.13 & $0.45^{\star *}$ & 1 & 0.19 & 0.15 \\
\hline$E Q^{a}$ & 0.17 & 0.11 & 0.82 & 0.12 & -0.25 & 0.19 & 1 & 0.11 \\
\hline WAl $^{b}$ & 0.87 & 0.29 & -0.27 & $0.27^{*}$ & 0.14 & 0.15 & 0.11 & 1 \\
\hline
\end{tabular}

${ }^{a} E Q$ : Empathy coefficient; ${ }^{b W A l: ~ W o r k ~ a b i l i t y ~ i n d e x ; ~}{ }^{*} p<0.05 ;{ }^{* *} p<0.01$ 
TABLE 4. Hierarchical multiple regression analysis of workability predict based on empathy and the perception of stress at work

\begin{tabular}{lccc}
\hline Predictor & \multicolumn{3}{c}{ Workability index } \\
\cline { 2 - 4 } & $\Delta R^{2}$ & $\beta$ & $\mathrm{F}$ \\
\hline Model 1 & $0.29^{\star}$ & & $6.39^{\star *}$ \\
$\quad$ Control variables & & & \\
Model 2 & $0.59^{* *}$ & & $41.48^{* *}$ \\
Gender & & 0.05 & \\
Total working internship & & 0.12 & \\
Empathy & & $0.39^{* *}$ & \\
Stress at work & & $0.54^{* *}$ & \\
Total $\mathrm{R}^{2}$ & $0.88^{\star *}$ & & \\
$\mathrm{n}$ & 100 & & \\
\hline
\end{tabular}

Control variables included gender and total working internship; ${ }^{*} p<0.05,{ }^{* *} p<0.001$

Dissatisfaction and lack of positive attitudes for work were significantly $(p<0.05)$ registered with health-care professionals from the intensive care unit. In terms of the past 3 months at work, a positive attitude and satisfaction at work have been observed in $13.5 \%$ of health professionals. Most health-care professionals only occasionally and rarely $(57.3 \%)$ have positive attitudes and satisfaction at work (Figure 1).

Approximately every third healthcare worker (35.2\%) estimated that in the next 2 years, they are not sure that they will retain the ability to perform their current work duties. Fewer $(9.1 \%)$ health-care professionals were sure that they will not be able to do the job in this period (Figure 2).

\section{DISCUSSION}

The concept of workability is not dependent only on health. It involves the broader context of living, above all the individual's existing abilities, his/her value system concerning work and social environment. Although physical health is the best predictor of working ability, research indicates the importance of psychosocial factors in workability decrease. As the most significant psychosocial factors, Gamperiene et al. highlight the ability to control work, the time limit for completing tasks, and leadership styles. A large number of studies have focused on identifying the types of stressors that adversely affect health-care professionals in intensive

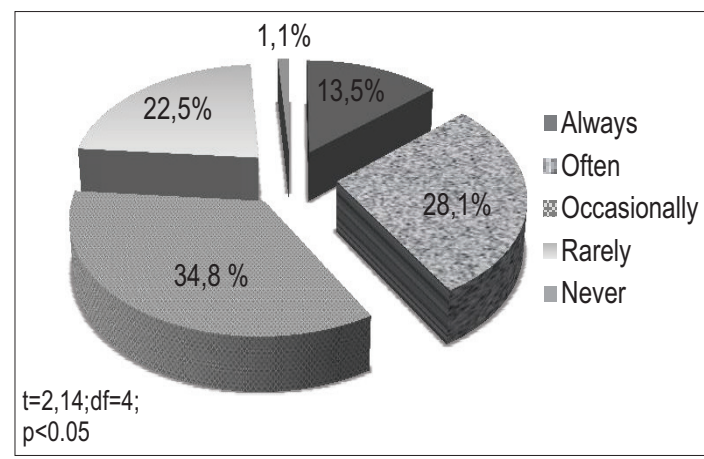

FIGURE 1. Distribution of positive attitude and satisfaction at work in the past 3 months.

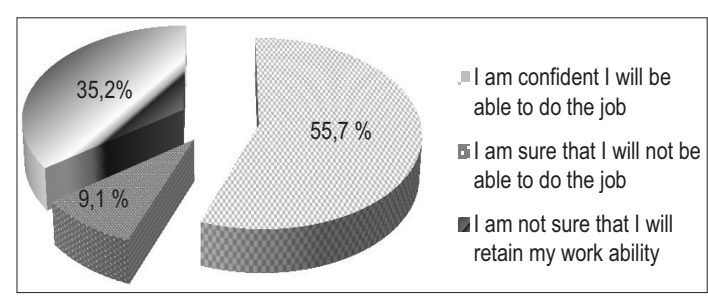

FIGURE 2. Health professionals' perceptions of working ability over the next 2 years.

care workplaces (19). The most intense stressors are mainly death and dying, physician conflicts, inadequate preparedness to assist the emotional needs of patients and their families, lack of support, conflict with colleagues, work norms, and treatment uncertainty (20).

Empathy and work commitment are, according to Raižienè and Endriulaitienè, significant predictors of emotional exhaustion that is a risk factor for burnout syndrome of health-care professionals (21). It often occurs with people who started their work with a lot of enthusiasm and expectation, with a strong desire to succeed or help others. Combustion at work involves changes in attitude toward work and changes in behavior toward patients, a progressive loss of idealism, energy, and meaningfulness of one's work (which does not happen in cases of usual fatigue).

In addition to work experience, place of work that is the clinical department of health-care professionals perform their work tasks significantly determines the development of empathy. Past experiences support the assumption that the amount of patient 
contact is a condition of empathy. The results of this study suggest that there are differences in empathy among health-care professionals working in departments with different patient contact. In both types of workplaces (intensive care units and other departments) average levels of empathy were registered, but the range of scores was lower in intensive care units. The results of the study by Newton et al. support the results of this research (22). The authors report that health-care professionals in the field of family medicine and pediatrics have more immediate empathy than their colleagues in the field of interventional medicine. The overall conclusion of their study is that health professionals in "people-oriented" areas (primary care, gynecology, emergency medicine, and psychiatry) score significantly higher than "technically-oriented" areas (surgery and surgical subspecialties). Furthermore, levels of occupational stress and its impact on physical health, psychological status, and job satisfaction across different professions were identified. The general conclusion of most studies is that the so-called assisting professions are the ones most exposed to the negative effect of stress. In a study by Weintraub et al., the prevalence of emotional fatigue in pediatric intensive care units was $15.7 \%$, burnout at work $20.8 \%$, and compassion satisfaction only $21.9 \%$ (23). They identify significant predictors of emotional fatigue: Female gender, unsupportive work environment, and avoidance of peer communication about difficult patients and stressful situations (23). At the same time, the empathetic response of the health-care professionals and the conversation about experiencing stressful situations between colleagues, such as debriefing techniques, have been identified as a preventative method for burnout syndrome and techniques of choice in coping with stress (24).

Occupational stress levels can be a health indicator of the health-care team in intensive care units. Stress adversely affects the health and quality of life of health-care professionals and the quality of health-care delivery. Burnout syndrome is associated with the organization and distribution of work, the increased number of overtime hours, frequent conflicts among staff and inadequate communication within the team. In the present study, the results suggest a negative effect of a limited number of stressors on the empathic capacity and work capacity of health-care professionals. The nature of work in different clinical departments determines the differences in the understanding of stressors as well as the effects on health professionals' workability and empathy. Work organization and finances are the most stressful for intensive care unit healthcare workers, while conflicts and inadequate communication at work were the main sources of stress for health-care professionals in other clinical departments. As a consequence of intense stress, there is a diminished empathy capacity of all health-care professionals, especially those working in intensive care units. Furthermore, a comparison of WAI scores in the intensive care unit indicates that the WAIs are significantly lower compared to other wards. Nowrouzi notes similar results in his study and highlights the emergency medical units with the lowest index values, explaining the results to a large number of patients, intense stress, quick decision making, and the nature of the work in these wards (25). Costa, based on the results of his study, points out that the intention to leave the workplace occurs twice as often in health-care professionals who have low WAI scores (26). The intention to change the profession initially grows but declines after the age of 30 , with WAI values also declining significantly with age. In our study, only $13.5 \%$ of the respondents show a positive attitude and satisfaction at work, while a third of them estimate that they will not be able to do this job in the next 2 years. Similar results were reported by other studies where 94\% of health-care professionals are considering leaving the profession and $54.7 \%$ have a negative attitude toward work and are dissatisfied (16). When added to the effects of aging, poor lifestyles, impaired physical health, and frequent illness, poor workability is inevitable (27).

Stress and burnout syndrome are negatively correlated with the WAI, while health perception and workability are positively correlated. On the other hand, stress and burnout are positively related to the intention to change profession (26). The results of independent studies, based on different models of occupational stress (28-31), have the same conclusions, and generally, one of the most serious consequences on the health-care professional's workability leaves burnout syndrome as a psychological state resulting from prolonged 
exposure to high-intensity stress during a professional engagement. The results of this study are consistent with the above and indicate that working conditions in the relation of stress and empathic capacity of health-care professionals are good predictors of workability. In addition to constantly dealing with the problems and suffering of its patients, it creates a psychological burden that depletes the emotional resources of health-care professionals.

\section{CONCLUSION}

Stress is present throughout the health profession, but some departments are riskier than others. Different stress perception among clinical departments is present. Due to work nature in intensive care units, health-care professionals have lower empathy scores and lower WAI index compared to other departments. Furthermore, in predicting workability in the next period, empathy and occupational stress are good predictors of workability. The complexity and importance of intensive care units go beyond the definition of a usual workplace for most people, but they also have their downside. Loss of ability to work, lack of empathy, and the risk of leaving the profession are some of the challenges for health-care professionals in intensive care units. Institutional and individual engagement in maintaining the health status of all health-care professionals, especially those in intensive care units is necessary.

\section{COMPETING INTERESTS}

All authors declare no conflicts of interest.

\section{REFERENCES}

1. Sullivan P. Pay more attention to your own health, physicians warned. CMAJ 1990;142(11):1309-10.

2. Maslach C, Schaufeli WB, Leiter MP. Job burnout. Annu Rev Psychol 2001;52:397-422.

https://doi.org/10.1146/annurev.psych.52.1.397.

3. Hockey GR. Compensatory control in the regulation of human performance under stress and high workload; a cognitive-energetical framework. Biol Psychol 1997;45(1):73-93. https://doi.org/10.1016/s0301-0511(96)05223-4

4. Baron-Cohen S. The Essential Difference: The Truth about the Male and Female Brain. New York: Basic Books; 2003. p. 213.

5. Gianakos D. Empathy revisited. Arch Intern Med 1996;156(2):135-6.

6. Larson EB, Yao X. Clinical empathy as emotional labor in the patient-physician relationship. JAMA 2005;293(9):1100-6.

https://doi.org/10.1001/jama.293.9.1100.
7. Lewis AE. Reducing burnout: Development of an oncology staff bereavement program. Oncol Nurs Forum 1999;26(6):1065-9.

8. Dunstone DC, Reames HR Jr. Physician satisfaction revisited. Soc Sc Med 2001;52(6):825-37.

9. Borman CW, Ilgen RD, Klimoski JR. Handbook of Psychology Industria and Organizational Psychology. Vol. 12. Chichester: John Wiley \& Sons; 2003.

10. Stansfeld S, Candy B. Psychosocial work environment and mental health--a meta-analytic review. Scand J Work Environ Health 2006;32(6):443-62. https://doi.org/10.5271/sjweh.1050.

11. Buddeberg-Fischer B, Klaghofer R, Buddeberg C. Stress at work and well-being in junior residents. Z Psychosom Med Psychother 2005;51(1):163-78

https://doi.org/10.13109/zptm.2005.51.2.163

12. Hasselhorn HM, Tackenberg $\mathrm{P}$, Müller BH. Working Conditions and Intent to Leave the Profession among Nursing Staff in Europe. Sweden: National Institute for Working Life; 2003.

13. Dajah SA, Daghdi AA. Prevalence and risk factors of low back pain among nurses in Sudayr region. Eur Sci J 2013;9(33):198-205.

14. AbuAIRub RF. Job stress, job performance, and social support among hospital nurses. J Nurs Scholarsh 2004;36(1):73-8.

https://doi.org/10.1111/j.1547-5069.2004.04016.x.

15. AbuAIRub RF, Al-Zaru IM. Job stress, recognition, job performance and intention to stay at work among Jordanian hospital nurses. J Nurs Manag 2008;16(3):227-36

https://doi.org/10.1111/j.1365-2834.2007.00810.x.

16. Ilmarinen J, Jarvisalo J, Koskinen S. Dimensions of Work Ability. Helsinki Results of the Health 2000 Survey; 1999.

17. Miloševic M, Kneževic $B$. Zdravlje na radu i odgovarajuća radna sposobnost zdravstvenih djelatnika. (Occupational health and adequate work capacity of health professionals). Cardiol Croat 2016;1:590.

18. Baron-Cohen S, Wheelwright S. The empathy quotient: An investigation of adults with Asperger syndrome or high functioning autism, and normal sex differences. J Autism Dev Disord 2004;34(2):163-75.

https://doi.org/10.1023/b: jadd.0000022607.19833.00.

19. Gamperiene M, Nygård JF, Sandanger I, Lau B, Bruusgaard D. Selfreported work ability of Norwegian women in relation to physical and mental health, and to the work environment. J Occup Med Toxicol 2008;3:8. https://doi.org/10.1186/1745-6673-3-8.

20. Gray-Toft P, Anderson JG. The nursing stress scale: Development of an instrument. J Behav Assess 1981;3:11-23.

21. Raiziene S, Endriulaitiene A. The relations among empathy, occupationa commitment, and emotional exhaustion of nurses. Medicina (Kaunas) 2007;43(5):425-31.

https://doi.org/10.3390/medicina43050052.

22. Newton BW, Savidge MA, Barber L, Cleveland E, Clardy J, Beeman G, et al Differences in medical students' empathy. Acad Med 2000;75(12):1215. https://doi.org/10.1097/00001888-200012000-00020.

23. Weintraub AS, Geithner EM, Stroustrup A, Waldman ED. Compassion fatigue, burnout and compassion satisfaction in neonatologists in the US. J Perinatol 2016;36(11):1021-6.

https://doi.org/10.1038/jp.2016.121.

24. Robins PM, Meltzer L, Zelikovsky N. The experience of secondary traumatic stress upon care providers working within a children's hospital J Pediatr Nurs 2009;24(4):270-9.

https://doi.org/10.1016/j.pedn.2008.03.007

25. Nowrouzi B. Quality of work life: Investigation of occupational stressors among obstetric nurses in Northeastern Ontario. Zahedan J Res Med Sci 2013;15:292-301. 
26. Costa AL. Cognitive Coaching: A Foundation for Renaissance Schools. Norwood, MA: Christopher-Gordan Publishers. 2002.

27. Fakhr-Movahedi A, Salsali M, Negharandeh R, Rahnavard Z. A qualitative content analysis of nurse-patient communication in Iranian nursing. Int Nurs Rev 2011;58:171-80.

https://doi.org/10.1111/j.1466-7657.2010.00861.x.

28. Glass DC, McKnigh JD. Perceived control, depressive symptomatology, and professional burnout: A review of the evidence. Psychol Health 1996;11:23-48.

https://doi.org/10.1080/08870449608401975.

29. Carter AJ, West MA. Sharing the burden: Teamwork in health care settings.
In: Payne RL, Firth-Cozens J, editors. Stress in Health Professionals: Psychological and Organisational Issues. Chichester, England: Wiley \& Sons; 1999. p. 191-202

30. Bakker AB, Schaufeli WB, Sixma HJ, Bosveld W, Dierendonck VD. Patient demands, lack of reciprocity, and burnout: A five-year longitudinal study among general practitionars. J Occupational Behav 2000;21:425-41.

https://doi.org/10.1002/(sici)1099-1379(200006)21:4<425:aid-job21 $>3.0 . \mathrm{co} ; 2-\#$.

31. Džubur A, Lisica D, Abdulahovic D, Avdic D, Smajovic M, Mulic M. Burnout syndrome in primary healthcare professionals. J Health Sci 2018;8:122-7. https://doi.org/10.17532/jhsci.2018.543. 